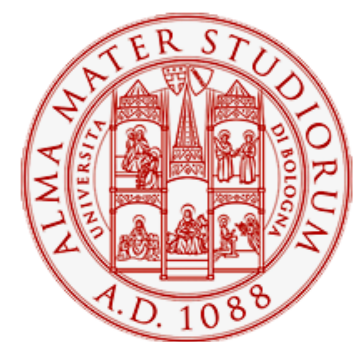

Alma Mater Studiorum - Università di Bologna DEPARTMENT OF ECONOMICS

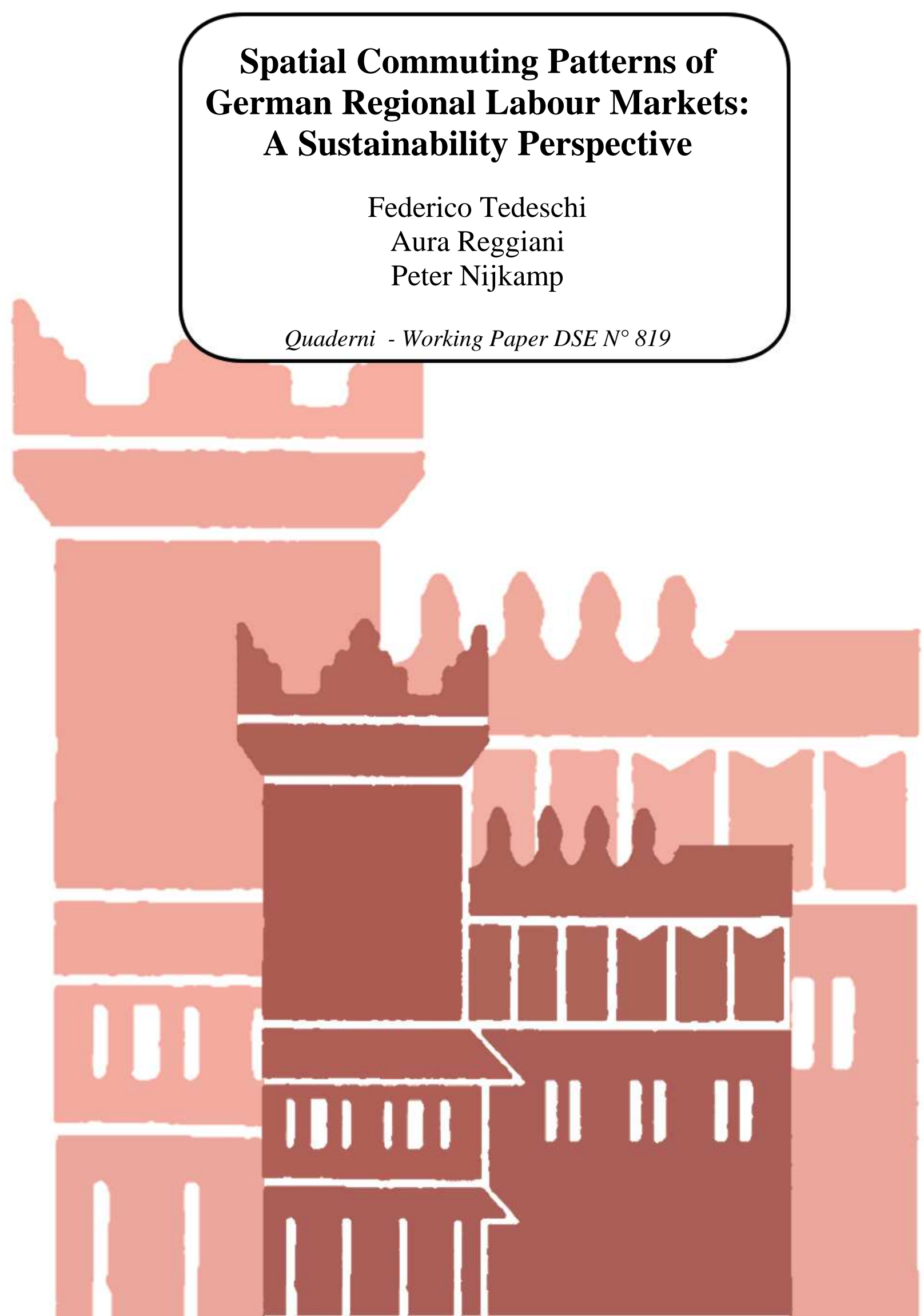




\title{
Spatial Commuting Patterns of German Regional Labour Markets: A Sustainability Perspective
}

\author{
Federico Tedeschi \\ University of Verona \\ Dept. of Public Health \& Community Medicine \\ Verona, Italy \\ federico.tedeschi@univr.it
}

\author{
Aura Reggiani \\ University of Bologna \\ Dept. of Economics \\ Bologna, Italy \\ aura.reggiani@unibo.it
}

\author{
Peter Nijkamp \\ VU University \\ Dept. of Spatial Economics \\ Amsterdam, The Netherlands \\ p.nijkamp@vu.nl
}

\begin{abstract}
This paper aims to investigate the relationship between commuting and spatial labour market developments in the framework of sustainability issues. To do so, we propose, first, an exploratory investigation of the effects of inbound commuter flows on employment in regional labour markets in Germany. Next, we address sustainability issues as a common umbrella for the relationship 'economy-transportation'. In this context, we show that the German production system is faced with negative environmental externalities, which are clearly associated with a specific transport mode, viz. the private car. Negative environmental externalities as a result of modal choices in Germany are confirmed by data from EU-15 countries. Public transport, in particular the train, appears to be more environmentally-benign.

Our results bring to light that, on average, commuter flows have a positive and robust effect on employment in the receiving German labour market districts, while, for commuting flows, public transport, especially the train, is a more environmentally-benign mode of transport, compared with the car, in reducing greenhouse gas emissions and energy consumption. In the light of possible policy strategies, the paper argues that sustainability may lead to positive economic effects; in particular, the improvement of the public transport system, which can provide more opportunities for sustainable commuting patterns, may lead to favourable employment perspectives for the local or regional labour force.
\end{abstract}

JEL Classification: R41, R23, J61

Keywords: Labour markets, employment, labour demand, commuting, public transport 


\section{Introduction}

Transportation and communication networks play a structuring role as the backbone of complex spatial connectivity patterns. Such networks have been instrumental in shaping a geographic interactive system that is governed by socio-economic forces in combination with business and labour market developments, and with the evolution of logistic and transport systems. Increasingly, modern spatial networks are moving from isolated modes to integrated and connected systems, in which - as well as a rise in use-intensity - both the geographical coverage and the time horizon are expanding.

Networks serve different purposes, and are thus subjected to various complex force fields. For example, freight networks display a trend towards high-value, low-weight goods, multimodal systems, differentiated markets, a strong dependence on ICT, and globalization. Information and communication networks are influenced by complex logistics developments, material and non-material substitution, advanced travel modes, and sophisticated ICT trends. And, finally, in the area of passenger transport we observe drastic demographic changes, a more leisure-oriented spatial behavioural pattern, and an increasing spatial action radius (see also Banister et al. 2000).

The development of these networks in Europe gives rise to a series of important policy and research challenges. Prominent issues are: the evolution of cities and urban areas (including urban sprawl); the need for sustainability and for ecologically-benign developments; the intermodal substitution within spatial transportation and communication networks; and the governance of spatial networks. In a study by Nijkamp et al. (2007), a strategic analysis of the key factors that act as drivers for, and impediments to, a sustainable spatial transport and interaction system are mapped out. A change in any of these factors may impact on both the efficiency and the sustainability of spatial mobility patterns. The evolution of spatial networks is determined by behavioural, psychological, institutional, economic and technological background factors. Technology plays a decisive role in network evolution, although its real impact is dependent on the design and acceptance of new client-oriented concepts (which are, in turn, dependent on behaviour and governance).

The present paper aims to map out and analyse the commuting patterns that are inherent in the dynamic functioning of German regional labour markets in the long run. These labour markets form a complex network of intertwined socio-economic systems, in which transport and interaction play a crucial role. After a statistical modelling experiment, the paper also 
pays attention to various sustainability aspects in the framework of the German economy. The study concludes with some methodological reflections and strategic observations. The paper is structured as follows: Section 2 and Section 3 are devoted to a literature review on the issues of, respectively, spatial systems and the relationship between spatial mobility and the labour market: Section 4 explores the link between the labour market and commuting in an empirical application relating to the German case. Section 5 focuses on the issue of sustainability, by analysing the interconnections between the economy, transport and environment, again with reference to the German situation. Section 6 concludes with some remarks on future research directions, also with respect to possible policy strategies.

\section{Spatial Systems' Evolution}

Spatial development at all geographical levels (local, regional, national, global) has a close association with transport and communication (see Black and Nijkamp 2002). An exposition on this complex interplay can be found in van Geenhuizen et al. (2002). For decades, trend analysis has been a popular tool to map out the development of spatial socio-economic and transport systems. But this approach has intrinsic limitations, as it is hard to incorporate technological innovations, behavioural processes and political-institutional changes and constraints. Nevertheless, there is a need for predicting future spatial and socio-economic patterns in a complex spatial system. This goal has led to more sophisticated modelling techniques which are also able to handle large-scale data (see, e.g., Gutiérrez-i-Puigarnau and Van Ommeren 2010; Nijkamp et al. 2007; Patuelli et al. 2011; Russo et al. 2010; Travisi et al. 2010). As well as new developments in spatial statistics and econometrics, scenario analysis has also become very popular as a means to understand complex systems (see Nijkamp et al. 1998, 2001). For example, the dynamics of spatial networks will be decisively influenced by urban sprawl, urban-rural developments, road-pricing mechanisms, intermodal competition based on new technological advances, international migration, labour supply, and the acceptance of new behavioural mobility patterns. Worldwide, the past few decades have witnessed far-reaching demographic shifts, new lifestyles, flexible production and work patterns, new policy priorities with respect to sustainable development, new requirements and conditions in policy making, and technological advances, all of which contribute to social change, as well as to spatial dynamics, including commuting. We are currently witnessing intriguing developments that can be described as concentration and uniformity at one level, and spread and differentiation at other levels, often in a polynuclear spatial configuration. In 
this context, transport and communication are important factors in shaping spread, differentiation, and agglomeration in our world. Clearly, bridging distance - whether physically or virtually - is associated with economic progress and a modern way of life. Spatial interaction (transport, commuting, trade, tourism, etc.) contributes in particular to efficient economic development, and gives actors a strong competitive position in an open and increasingly global network society. Admittedly, it is also increasingly being recognized that a mobile society incurs high social costs, and causes a variety of negative externalities, including traffic congestion, accidents and fatalities, pollution, and noise nuisance, destruction of the beauty of the visual landscape (both the townscape and the countryside), waste in the use of resources, raw materials, energy, and so forth. An important market-disturbing factor is that, in general, social costs are not charged to the transport user, but to other social categories who are not directly involved in the transport decision. At the same time, the demand for transport is increasing, especially in those sectors that are relatively the most polluting, viz. road and air. For example, over the past 25 years, private car use in Europe has more than doubled, while in the same period road freight has also risen significantly (by more than 50 per cent). The extrapolation of current trends would lead not only to an unacceptable high level of environmental decay, but also to serious disparities in the accessibility of congested regions and cities. Accordingly, the overall picture of a modern transport network is rather problematic: the demand for transport services is rapidly rising, causing increasing stress on the environmental system and on the quality of life, and thus on sustainable development.

It comes almost as a surprise that strategic knowledge about the complexity of transport systems is still limited, especially from a long-term perspective. A transport system may show rather unexpected turbulence as a result of interacting forces between dynamic behaviour and limits to capacity. This may hold not only for daily traffic flows but also for changes in patterns of international trade or tourism. There is a serious lack of insights into how actors in transport respond to policy measures, particularly cost measures (for an exception, see Stathopoulos et al. 2011), while at the same time there is a need to fine-tune goals, measures, and the social acceptability of a mobile society.

In our era, transport and communication are contributing to trends for spread and geographic heterogeneity, and simultaneously the global network society is inducing new forms of communication, interaction, and mobility. In an open and individualizing society, there seems to be an ongoing move towards a mobile society, and away from the homebound society, although there still seems to be a structural discrepancy in the behaviour of the rich and the poor, which has implications for commuting pattern. In this respect, high-income 
groups and the well-educated are usually more mobile and are exhibiting a persistent preference for living in suburban locations, except for a few respectable inner-city quarters. A counterbalancing factor is that the growing constraints in physical infrastructure, evident mainly in road traffic congestion, will inevitably lead to severe congestion on major traffic routes and the loss of the attractiveness of particular suburban locations. Smart logistic concepts and adequate policy solutions are still to be found, but they may entail a combination of measures, such as a more efficient use of existing transport systems and a selective increase in physical infrastructure, while respecting the need for urban sustainability.

A number of shortcomings in the policy-making process can clearly be observed, such as in the design of alternative options for sustainable solutions. We often observe a situation of 'forgotten' alternative choice options, owing to an uncritical quick (or a-priori-selected) generation of strategic options. Clearly, there is no systematic and transparent generation of strategic alternatives for sustainable mobility. There is surprisingly little recognition of how large a benefit must be, before it is considered significant enough to change a policy. There is also a lack of valuation criteria with respect to specific impacts (such as societal and equality costs and environmental costs), although there is a clear need to systematically include these impacts in the analysis (see also Bakker et al. 2010).

An important integrative, but often neglected, concept in relation to sustainable transport is the strategic conceptualization of spatial systems. The awareness of complexity in mobility systems (and partly chaotic development) has in recent years opened the door to dynamic modelling based on notions from evolutionary economics, network-niches, and chaos models (Nijkamp and Reggiani 1998; Reggiani and Nijkamp 2009). The challenge here lies in empirical testing based on solid data. In addition, the concept of networks raises questions on the side of user-appreciation. In this context, interconnectivity is an important aim in improving the users' appreciation of transport systems, and in increasing spatial efficiency in a mobile society. In the framework of the present paper we now address more in particular the mobility dimensions of regional labour markets, and their consequences for sustainable development.

\section{Spatial Mobility and the Labour Market}

The need for a solid economic analysis of the performance of transportation systems from the point of view of policy makers was already stressed some decades ago by Nobel-prize winner McFadden, who highlighted its importance for urban economics (McFadden 1974). This has 
led to a strand of literature on transport systems, commuting, and location. For example, in a model where all employment is located in the centre, Brown (1986) introduced the simultaneous choice of housing volumes, residential location, and work-trip mode. The author linked the theory on urban economics to that on urban transportation planning, and found that trip mode and residential location choice are not independent. In the same vein, Maat and Timmermans (2009) showed that commuter trips have a major impact on car use, and that commuting mode varies with both socio-demographic and spatial variables. People's modal choice is determined more by work location than by residential location. In order to develop policies to reduce car use, these authors propose to design work locations - rather than residential locations - to be more compact and more accessible by public transport modes and bicycles.

Accessibility can thus be considered a driving force in the modal choice of commuters. Also the urban form of the work location has a stronger influence on modal choice than that of residential location (Cervero 1996). The increasing sprawl of housing and work is also identified as an important factor for the increasing car use (Geurs and Van Wee 2006).

With respect to sustainability issues, the kind of vehicles mainly used for the transport system is considered to be a crucial factor. Kenworthy et al. (2005) stress the importance of this topic: whether the transport system is mainly based on private car use or on public transport is relevant for the whole economy. Given the relevance of a sustainable transport system, this is a topic that needs to be taken into account by policy makers in terms of financing and pricing infrastructure, regulations (e.g. in terms of emissions per car, speed limit, safety, etc.), taxes, fees and subsidies, land use, parking policy, and logistics (see Nijkamp et al. 2005). Consequently, all these measures influence spatial mobility and labour markets (clearly, with complicated feedback effects).

To achieve an appropriate balance between the social costs and benefits of policy interventions related to the transportation system, the labour market is one of the key mechanisms to be taken into consideration. A particular aspect of labour markets that is more directly connected with sustainable transport is commuting. For instance, commuting flows may improve employment perspectives in the receiving areas. Therefore, an increase in accessibility would have positive socio-economic effects on labour markets. How to enforce this (i.e. whether the public or private transport system is expanded) certainly has an impact on sustainability, which would, therefore, become a more crucial and strategic concept.

Moreover, increasing sustainability (for example, by improving the public transport system to induce people to choose it) may reduce either the cost or the time of the journey-to- 
work, and therefore increase commuting flows. For example, in a model of joint decisions concerning where to live and work and how to travel to the workplace, Li et al. (2010) find that transportation improvements which decrease commuting time will not only increase commuting trips but also affect residential location (making people more likely to accept a greater distance from their workplace) (see also Rouwendal and Nijkamp 2010). Clearly, current spatial dynamics stimulate various mobility processes that are characterized by a wide array of externalities.

In this context, the European Policy Center (EPC, 2005) describes sustainability as a social need to be combined with economic growth, while simultaneously including, among sustainability issues, the financing of infrastructures. Regarding the latter, the EPC recommends market-based incentives as guiding principles for investments in transport. EU (2011) includes efficiency and cost-effectiveness among the purposes of a sustainable transport plan, together with making accessibility available to all. In the same vein, with respect to transport in the US, Behrens et al. (2011) discuss how the elimination of trade and urban frictions may lead to productivity gains.

In the light of the previous observations, it may be meaningful to offer some reflections on the labour market system, in order to lay a theoretical foundation for analysing commuting phenomena in a spatial labour market context.

\section{Labour Markets and Commuting}

\subsection{A selective literature overview}

In the traditional competitive model of the labour market, wages are set in order to match supply and demand. Wages across labour markets may differ, therefore leading workers to either relocate or commute in their search for higher wages. This should set the equilibrium wage uniform across labour markets.

There are several criticisms of this model. Since wage differentials among employees arose, income distribution was related to human capital (reflected in the "Mincer equations", in the 1970s; see Mincer 1974). Later, with the availability of panel data sets in the 1980s, the residuals from the Mincer equations underlined that there was a part of wage heterogeneity which was left unexplained. Theory suggested this could be accounted for by the unobservable heterogeneity of human capital and by productivity shocks.

However, all these models assume perfect information, and therefore wages are determined by individual productivity alone (see Heckmann and Honoré 1990). On the 
contrary, with the advent of matched employer-employee data at the end of the 1990s, it became clear that these models could not take all wage dispersion into account. Therefore, new models were proposed, allowing for search frictions due to information imperfection. In particular, equilibrium search models assume that unemployed workers randomly sample job offers by firms with vacancies, and decide whether to accept or refuse an offer based on their expected utility.

The basic model in this context was proposed by Burdett and Mortensen (1998). Extensions of the model include the possibility for employers to counter outside offers made to their employees (Postel-Vinay and Robin 2002), the inclusion of productivity shocks (Postel-Vinay and Turon 2005), and the exogeneity of the wage distribution (Jolivet et al. 2006).

All these departures from the basic competitive model do not, however, change the crucial point: assuming homogeneity of wages among equally-skilled employees would make workers willing to move to markets where equivalent workers are paid more, while the inclusion of randomness in the job-matching is a further reason why unemployed workers could accept relocating or commuting to different labour markets. Examples of models of labour market equilibrium where the supply side includes the commuting distance implied by residential and location choice may be found in Simpson (1992) and Sorek (2009).

From the perspective of the impact of commuting on the employment level of the receiving local labour market, it is noteworthy that both positive and negative effects may occur. In fact, commuters may crowd out local workers from available jobs (leading to a negative effect: see Hazans, 2005). At the same time, however, they increase the availability of workers, thus encouraging the creation of new vacancies (see Pierrard, 2008). In addition, they can lead to a rise in local employment also in an indirect way, i.e. their impact on local demand: as long as they make their expenditures in the receiving local labour market, they increase consumption levels and demand for local services, as argued by Hazans (2005). Finally, the issue of the impact of commuting on the optimal provision of local public goods is analysed by Shields and Shideler (2003), who propose a model to determine the optimal commuting tax size for Pennsylvania's municipalities.

The above-mentioned literature argues essentially that commuters may generate both virtuous and vicious outcomes for the locals, and that, as in the case of migration, complementary and substitution effects may arise. With regard to employment in the destination region, commuting inflows may be expected to have two main contrasting effects on local employment: (i) commuters may cause new job creation for the locals by raising the 
demand for local goods and services (for example, public transport); and, in contrast, (ii) they are likely to crowd out some residents, since they compete with them for the available jobs. A comparison of the findings from Hazans (2005) and Pierrard (2008) highlights that the question which of the two forces will prevail is an empirical one. Consequently, we will put this question to an empirical test, in which the commuting effects on labour markets are explicitly modelled, with reference to the German case (see Section 4.2).

In the German context, Stutzer and Frey (2008) analyse commuting decisions from the perspective of equilibrium theory, finding that people usually commute for longer travel times than would be expected from individual utility maximization. Buehler (2009) argues that Germany possesses a much better transport system compared with the USA, owing to an efficient use of government subsidies, a high quality of public transport supply, various policies discouraging car use, and the integration of, and coordination between, different modes of transport and across regions. The debate about public transport in Germany has become increasingly relevant in the last two decades, due to decentralizion and re-regulation according to new EU-directives, as highlighted by Brandt (2006). Various issues related to the economic and environmental effects of incentives and subsidies linked to public transport in Germany are addressed by Berg et al. (2010) and Hirte and Tscharaktschiew (2011), while the adoption of incentives to use public transport instead of encouraging urban road transport is also advocated.

Starting from the above considerations, we now analyse the relationship between commuting and employment with reference to the 439 German labour market districts (Section 4.2). Next, we explore the environmental impacts in relation to GDP in Germany (and hence also of transportation), seen from the broader perspective of European sustainability (Section 5)..

We first provide an empirical analysis of the effects of commuting on employment outcomes for workers in the receiving German labour market regions.

\subsection{Labour Markets and Commuting: A German Case Study}

\subsubsection{Database and model adopted}

The first part of our empirical analysis is devoted to the identification of the effects of commuting flows on given spatial labour market outcomes ${ }^{1}$. The data set available is based on IAB (Institut fur Arbeitsmarkt und Berufsforschung) data related to the 439 German districts

\footnotetext{
${ }^{1}$ Section 4.2 is an adapted version of Russo et al. (2010).
} 
(Kreise) at the NUTS 3 level, for the years 1996-2005. The data record commuting flows between all pairs of districts, population of working age (15-64,WAP ${ }_{i}$ hereafter), place of residence of workers, and labour demand, i.e. the number of workers enrolled in the social security system and working in a given district ${ }^{2}$.

Out-commuting (people living in $i$, but working in a different German district, denoted by $E$ ) and in-commuting (workers employed in district $i$, but who live somewhere else in Germany, denoted by $I$ ) imply that the number of workers ( $W_{i}$ hereafter) typically differs from the number of resident employed workers $\left(R E W_{i}\right.$ hereafter), in a given district $i$. Formally, this is:

$$
R E W_{i}=W_{i}+E_{i}-I_{i}
$$

The presence of commuters may generate positive labour demand externalities (by decreasing the cost of opening a vacancy: see, for example, Pierrard 2008). Furthermore, commuting inflows and outflows might be positively correlated: residents crowded out may find a new job in another district, therefore becoming commuters themselves. This implies that inbound commuters, who outbid natives do not necessarily either increase local unemployment or cause a decrease in available jobs ${ }^{3}$.

Therefore, we consider the effect of commuting both on the number of jobs in district $i$ and on the demand for local labour (denoted by $D L L_{i}$ ), given by:

$$
D L L_{i}=W_{i}-I_{i}=R E W_{i}-E_{i}
$$

Since economies of scale (market-size effect) in labour creation and employment may also prevail, we divide the variables in Equations [1] and [2] by the regional working age population in order to obtain employment (and labour demand)-to-population ratios.

Therefore, the variables we focus on in our empirical analysis are:

\footnotetext{
${ }^{2}$ The data come from the administrative records of all employed persons in Germany, and are recorded in the month of June of each year. Only when there are at least 3 commuters, are the flows recorded. This data set was then complemented with demographic data extracted from the regional data bank of EUROSTAT. For details, see Russo et al. (2010).

${ }^{3}$ For a similar mechanism in the case of migration, see, for example, Card and DiNardo (2000). We find that the correlation between the inflow rates and the outflow rates over time by district is positive in the majority of cases: 241 districts, but it is also negative for a large number of districts: 198. To draw a definitive conclusion, we ought to be able to compare homogeneous groups of workers with respect to skill type and educational attainment (Card and DiNardo 2000).
} 
- $\quad$ the employment-to-population ratio $\left(E P R_{i}\right.$ hereafter), given by the ratio of resident employed workers to the working age population of the district:

$$
E P R_{i}=\frac{R E W_{i}}{W A P_{i}}
$$

local labour demand density (the number of jobs divided by the regional working age population, denoted by $\left.L L D_{i}\right)$ :

$$
L L D_{i}=\frac{W_{i}}{W A P_{i}}
$$

local workers' rate (denoted by $L W R_{i}$ ), given by the fraction of local jobs filled by workers living in the same region:

$$
L W R_{i}=\frac{D L L_{i}}{W_{i}} .
$$

The analysis of the impact of inbound commuter flows on each of the above-mentioned variables will be carried out with the use of fixed-effects panel models, because of the presence of unobserved district characteristics which are likely to be stable and correlated with the regressors ${ }^{4}$. Moreover, national German $\mathrm{GDP}^{5}$ has been included as well, in order to account for the evolution of global economic conditions. The adopted model is described in detail in the next section.

\subsubsection{The identification strategy: OLS models}

We first estimate the impact of commuting on local economic performance variables using the following models (see also Russo et al., 2010):

$$
\begin{gathered}
E P R_{i t}=v I_{i t}+\beta_{1} G D P_{i t}+\beta_{1}^{*} G D P_{t}+\delta_{1} D E N S_{i t}+\lambda_{1 i}+\varepsilon_{1 i t} \\
L L D_{i t}=\kappa d_{i t}+\beta_{2} G D P_{i t}+\beta_{2}^{*} G D P_{t}+\delta_{2} D E N S_{i t}+\lambda_{2 i}+\varepsilon_{2 i t}
\end{gathered}
$$

\footnotetext{
${ }^{4}$ Such variables include the industry sector, average wage levels, educational levels, skills, and the age composition of the workers. All the analyses have been performed both with fixed- and random-effect specifications. However, the fixed-effect specification is always supported by the Hausman specification tests (when feasible).

${ }^{5}$ At real prices, using the price level in year 2001.
} 


$$
L W R_{i t}=\alpha I_{i t}+\beta_{3} G D P_{i t}+\beta_{3}^{*} G D P_{t}+\delta_{3} D E N S_{i t}+\lambda_{3 i}+\varepsilon_{3 i t}
$$

where subscript $i$ denotes districts, and subscript $t$ time. $E P R_{i t}, L L D_{i t} L W R_{i t}{ }^{6}$ (as defined in the previous section), $I_{i t}, G D P_{i t}$ and $P O P_{i t}$ are thus related to district $i$ at time $t$. In particular, $I_{i t}$ is the logarithm of the global number of commuting inflows divided by 1,$000 ; G D P_{i t}$ and $G D P_{t}$ are the logarithms of the value added at current prices (at district and national level, respectively); and $P O P_{i t}$ is the density of population (number of inhabitants per 1,000 square metres). The parameters $\lambda$ are fixed effects relating to time and district (that may be correlated with the regressors), while $v, \beta, \kappa, \alpha$ and $\delta$ are the parameters to be estimated. Finally, $\varepsilon$ is a random error term following the usual $O L S$ assumptions.

The effects of commuting inflows on the relevant outcome variables are then expressed by the parameters $v, \kappa, \alpha$. The results of the regressions are shown in Table 1, where we find a positive effect of commuting inflows on the employment-to-population rate, and on the number of jobs in the district, and a negative impact of the commuting inflows on the local workers rate ${ }^{7}$.

Table 1: District OLS fixed-effect estimates of the effect of commuter flows

\begin{tabular}{lccc} 
VARIABLES & logitEPR & LLD & logitLWR \\
\hline Lninflow $\left(\mathrm{I}_{\mathrm{it}}\right)$ & $0.065^{* * *}$ & $0.106 * * *$ & $-0.713^{* * *}$ \\
\hline & $(0.009)$ & $(0.004)$ & $(0.014)$ \\
\hline Lngdp $\left(\mathrm{GDP}_{\mathrm{it}}\right)$ & $-0.068^{*}$ & 0.057 & $-0.141 * * *$ \\
\hline & $(0.016)$ & $(0.006)$ & $(0.022)$ \\
\hline Denspop $\left(\mathrm{POP}_{\mathrm{it}}\right)$ & $-0.033^{* * *}$ & $0.018^{* * *}$ & $0.247 * * *$ \\
\hline & $(0.011)$ & $(0.005)$ & $(0.022)$
\end{tabular}

Note: Standard errors in parentheses; *** significant at the $1 \%$ level, ** significant at the 5\% level, *significant at the $10 \%$ level.

\subsubsection{The endogeneity issue}

As stated above, we are here analysing the effect of commuting flows on given employment outcomes. However, we should admit that reverse causality may also hold: a strong economy

\footnotetext{
${ }^{6}$ In the case of $E P R$ and $L W R$, we take their logit transformation: since the level variable ranges between 0 and 1 , this leads to an outcome variable whose domain is the whole set of real values.

${ }^{7}$ The results are robust to different specifications of the outcome variables and of the inflows: the sign and significance of the results do not change, neither in a linear probability model (for $E P R$ and $L W R$ ) nor when the inflow of commuters is in linear form.
} 
with high job creation might also attract commuting flows ${ }^{8}$. Therefore, the direct regression of the employment variables of interest on commuting flows may not be considered as a causal relationship. The most natural way to deal with this source of bias is to adopt an Instrumental Variable ( $I V$ hereafter) method, i.e. a variable correlated to the endogenous regressor, but exogenous with respect to the dependent variable ${ }^{9}$.

Consequently, we need a variable correlated to commuting, and affecting employment outcomes only through commuting itself. Changes in regional fiscal policies affecting the tax regime that characterizes commuting costs (or wage compensation for commuting) seem to fit this requirement. Since the subsidy system related to commuting distance has changed twice in our reference period (in years 2001 and $2004^{10}$ ), we have the possibility to build an instrument with these characteristics. In particular, we consider two dummy variables related to time, assuming values of 1 for the years from 2001 to 2003 (we denote such a variable as $\mathrm{T}_{1}$ ) and for the years 2004 and 2005 (this variable is defined as $\mathrm{T}_{2}$ ). Following the wealth of literature on panel model estimations (see, for example, Griliches and Hausman, 1986), we have chosen the lagged value of commuter flows as a further instrument.

We have analysed different combinations of these possible instruments, following a two-stage-least-squares estimator ${ }^{11}$ approach. The model that has finally been adopted includes the lagged values of inflows, together with the squared amount of the subsidy related to each kilometre after the $10^{\text {th }}$ one $^{12}$ (among the possible different multiple-instruments settings, this is the only case where the Sargan test has never been rejected ${ }^{13}$ ). The regression chosen in the first stage is thus given by:

$$
I_{i t}=\beta_{4} G D P_{i t}+\beta_{4}^{*} G D P_{t}+\delta_{5} D E N S_{i t}+\Phi I_{i, t-1}+\eta_{1} T_{s q}+\lambda_{5 i}
$$

\footnotetext{
${ }^{8}$ In the scientific literature, commuting is often considered as the outcome of, among other things, several behavioural variables linked to the functioning of the labour market (see, e.g., Shields and Swenson 2000; Hazans 2003).

${ }^{9}$ For a review on this topic and formal definitions, see Pearl (2000) and Angrist and Krueger (2001).

${ }^{10}$ From 2001 to 2003 , the subsidy system was: $€ 0.36$ for every kilometre up to $10 \mathrm{~km}$ distance and $€ 0.40$ for every kilometre more than $10 \mathrm{~km}$, while, from 2004, the system was changed to $€ 0.30$ for every kilometre (regardless of distance).

${ }^{11}$ This implies an estimation of inflows to each district (first stage).

${ }^{12}$ This instrument is in line with increasing returns of the subsidy, meaning that each marginal euro has a greater effect on the commuting decision.

${ }^{13}$ In all cases, the p-value is always above 0.36 ,while, for all the other models adopted, the p-value was highly significant $(<0.001$ in at least one regression).
} 
where regressors, parameters and subscript $i, t$ have the same interpretation of the $O L S$ case; $\Phi$ refers to the lagged value of inflows; and $\eta_{1}$ refers to the squared value of the subsidy received for each kilometre of commuting distance exceeding the $10^{\text {th }}$ one. In the second stage, fitted values from this regression are then used as our $I V$ for the final regression analysis.

The results from the $I V$ estimates are shown in Table $2^{14}$ and do not appear to depend on the transformation of the dependent variable chosen ${ }^{15}$. A comparison with the $O L S$ results in Table 1 highlights that the estimates of the effects of commuting inflows on our outcome variables have increased, apart from the case of the regression concerning local workers rate: in this case, the related parameter value turns out to be similar to that emerging in the $O L S$ analysis.

To sum up, our IV models confirm that commuter flows tend to increase employment and job opportunities in the receiving districts; in addition, the effects estimated in our $O L S$ models do not appear to be downward-biased. Nevertheless, we are not able to assess the magnitude of these effects: to check robustness of our results, the availability either of different instruments (possibly allowed to vary at the district level ${ }^{16}$ ) or of a longer time $\operatorname{span}{ }^{17}$ would be necessary.

Table 2: District IV fixed-effect estimates of the effect of commuter flows (equation 9)

\begin{tabular}{lccc} 
VARIABLES & logitEPR & LLD & logitLWR \\
\hline Lninflow $\left(\mathrm{I}_{\mathrm{it}}\right)$ & $0.126^{* * *}$ & $0.138^{* * *}$ & $-0.718^{* * *}$ \\
\hline Lngdp $\left(\mathrm{GDP}_{\mathrm{it}}\right)$ & $(0.022)$ & $(0.007)$ & $(0.024)$ \\
\hline & $-0.060^{* * *}$ & 0.001 & $-0.132 * * *$ \\
\hline & $(0.021)$ & $(0.007)$ & $(0.023)$ \\
\hline
\end{tabular}

\footnotetext{
${ }^{14}$ Regressions are performed using fixed-effect models. Tests on under-identification (Cragg-Donald Wald $F$ statistics), weak-identification (Andersson $L M$ statistics), and $F$-tests on the significance of instruments in the first-stage regression all indicate that the instruments are relevant. In particular, the $F$-test value for the logarithm of inflows is 1456.658 .

${ }^{15}$ In the case of $E P R$ and $L W R$, we also used the level of the dependent variable instead of its logit transformation: the results on the sign and significance of the relevant coefficients do not change.

${ }^{16}$ The need for this kind of $I V$ is highlighted by the fact that inclusion of a district-varying instrumental variable (as the lagged values of inflows) strongly reduces the ranges of confidence intervals, compared with other $I V$ models we have tried, which used only information about subsidies to build our instrument.

${ }^{17}$ In this case, a proper Regression Discontinuity Design could be built.
} 


\begin{tabular}{|c|c|c|c|}
\hline Denspop $\left(\mathrm{POP}_{\mathrm{it}}\right)$ & $0.308 * * *$ & $0.032 * * *$ & $0.294 * * *$ \\
\hline & $(0.027)$ & $(0.008)$ & $(0.029)$ \\
\hline
\end{tabular}

Note: Standard errors in parentheses; $* * *$ significant at the $1 \%$ level, $* *$ significant at the $5 \%$ level, $*$ significant at the $10 \%$ level.

Given this direct relationship between commuting and the German labour market, and given the fact that the private car represents the prevalent mode (about 65 per cent) for commuting trips in Germany, with consequent environmental damage, the next step in our analysis is the exploration of the relevance of modal choice for commuting, from the perspective of sustainability issues.

In this context, we first (Section 5.1) turn our attention to the relationship between sustainability and GDP in Germany (given the hypothesis that economic growth has a negative environmental impact owing to an increase in car use as a commuting mode), while next (Section 5.2) we offer a tentative analysis of the environmental performance of transport modes in Germany.

\section{Economy and Transport: a Sustainability Framework}

\subsection{Economy, transport and environment in Germany}

"Transportation is a measure of economic activity: in many instances, it may be a leading indicator, inasmuch as physical movements precede financial transactions. Transportation is a reflection of economic activity, inasmuch as products must be moved to markets. Some of these relationships are clearly circular: transportation affects economic conditions, and economic conditions influence transportation" (Norwood and Casey, 2002, pp. 22-23).

Clearly, it is not easy to fully understand and model the complex relationship between transportation and the economy. This section is devoted to a subsequent step in our analysis, viz. the environmental impacts of economic activities, by taking into account environmental indicators conventionally used for measuring transport emissions. In this way, we attempt to model an 'indirect' relationship between the economy and transport, by means of environmental indicators.

With reference to the European situation, it is important to note that, since the 1992 White Paper "The Future Development of the Common Transport Policy" and the 2001 White 
Paper "European Transport Policy for 2010: Time to Decide", the European Union has sought to tackle the issue of providing efficient, effective and sustainable transportation systems. In particular, the overall strategy consists of: i) providing affordable and high-quality transport; ii) protecting the environment; iii) providing incentives for technological innovations; and iv) providing incentives for international interconnectivity. The intention is that these objectives should be achieved by a decoupling process between the growth of transport and economic growth, and by providing incentives to shift to more environmentally-friendly modes (Percoco and Reggiani 2008). In this context, the need for a comprehensive analysis concerning the effects of different environmental policies is pertinent.

As economic policies also depend on the strength of the institutional context, Infante and Smirnova (2011) focus on the regulatory constellations of society. In particular, they propose new models to estimate the impact of the institutional context on anti-pollution legislation, environmental quality, and social welfare. They perform a differentiated analysis for groups of countries, by identifying the impact of the quality of the institutional context on the position of the turning point of what is called the environmental Kuznets curve (see Kuznets, 1955).

Starting from these general considerations, this final step of our analysis is to explore the relationship between GDP and environmentally-sustainable transport in Germany, Given the strict relationship between GDP and the commuting/labour market, as shown in the previous section, a close connection between transport pollutants and GDP has also to be expected. As underlined by WBCSD (2001), the dependence of transport on fossil fuels makes it one of the main causes of the emission of greenhouse gases, i.e. gases regulated by the Kyoto Protocol (in the case of transport: carbon dioxide, methane, and nitrous oxide). In our analysis, we use nitrogen dioxide (belonging to the same family as nitrous oxide, i.e. the nitrogen oxides) as an environmental indicator, given the data availability with regard to this kind of energy consumption for a relevant time-period at the "Lander" level in Germany ${ }^{18}$.

Three different variables related to nitrous oxide are considered: the median yearly value of emissions; the maximum hourly value of emissions (in both cases, in milligrams in cubic meters); and a dummy variable indicating whether at least on one day (for each given year) emissions have exceeded a given threshold (200 milligrams in cubic meters). Since

${ }^{18}$ The "Lander" are the 16 Federal States into which Germany is divided, corresponding to the EU NUTS1 level. 
many stations measure nitrogen dioxide in each "Lander", the highest value has always been taken into account ${ }^{19}$.

Next, we first perform simple regressions - using German data at the "Lander" level, available from UBA (Umwelt Bundes Amt) - between these variables and GDP at real values (in the regressions performed in Section 4) for the period 2001-2006. We find a significant parameter only for the regression related to the dummy variable. We then perform crosssection regressions on the same data set, using "Lander"-specific fixed-effects. These results show that GDP turns out not to be significant, regardless of the nitrogen oxide indicator used. The outcomes of both OLS and fixed-effect regressions are given in Table 3.

Table 3: Cross-section estimates (with district-fixed effect) of GDP on nitrogen-dioxide emissions variables ( German "Lander"; years 2001-2006)

VARIABLES OLS regressions $\quad$ Fixed-effect

\begin{tabular}{lcc} 
Yearly emissions & \multicolumn{2}{c}{ regressions } \\
Hourly emissions & $8.506(6.080)$ & $-31.230(36.308)$ \\
Emissions above $200 \mathrm{mg} / \mathrm{m}^{\wedge} 3$ & $5.294(1.265)^{* * *}$ & $-38.247(127.322)$ \\
& & $-9.451(8.309)$
\end{tabular}

Note: Standard errors in parentheses; *** significant at the $1 \%$ level, ** significant at the $5 \%$ level, *significant at the $10 \%$ level.

We have been able to trace how GDP may affect variables related to environmental performance (as a proxy for transport emissions) in the German "Lander". In particular, we find a significant relationship between GDP at real values and emissions of nitrogen dioxide above given thresholds, as shown in Appendix 1.

However, such a relationship disappears once we control for the "Lander" effects. Thus, we find that "Lander" with a higher GDP also have more frequent extreme emissions of nitrogen dioxide, but that such a relationship does not hold once we control for "Lander"specific characteristics.

All in all, these results are clearly consistent with the hypothesis that economic growth (expressed by an increases in GDP) has not led Germany to an environmental awareness, which seeks to produce lower levels of energy use and pollution. These results confirm recent

\footnotetext{
${ }^{19}$ In the case of binary variables, we have thus considered whether the given threshold has been exceeded by at least one station on at least one day.
} 
findings which position Germany around the turning point of the Kuznets curve, i.e. high GDP, but also high emissions (Percoco and Reggiani 2008).

Recent research has shown an increasing trend of negative externalities linked to private car use (Woodcock et al. 2007). With respect to the relationships between urban form and infrastructure - for instance, on the role of the compact city in sustainability - some authors argue that compact cities - because of their high-density land use - are inherently more environmentally-efficient, since distances tend to be shorter (see, e.g., Woodcock et al. 2007). On the other hand, recent research (Gaigné et al. 2011) shows that a decentralization of jobs may be more environmentally-desirable. In summary, the debate on monocentric vs. polycentric cities - in the light of the best ecological performance - seems to emphasize the relevance of a balance between the level of population density and the spatial pattern of economic activities (polycentric within monocentric structures). It is evident that the concentration-deconcentration dilemma is also clearly connected with the available transport modalities (e.g. public transport vs. private transport). Against this background, we now examine the environmental performance of train use vs. car use in Germany.

\subsection{Transport modes and environmental performance in Germany}

Given the impact of commuting on labour markets in Germany, as discussed in Section 4, as well as the relationship between transport emissions and GDP (see Section 5.1), it is more pertinent to address the environmental performance of transport modes more directly. In fact, while we have seen that GDP is related to (transport) pollution, we have not yet analysed how environmental indicators (at a given GDP level) may change in association with the transport mode adopted.

In this context, an interesting environmental indicator is the consumption of energy: in fact, the energy intensity of land transport is clearly correlated (together with other adverse health effects) with environmental degradation, as pointed out by Woodcock et al. (2007). In particular, road transportation accounts for 81 per cent of total energy use by the transport sector (Chapman 2007). Since transport is almost completely reliant upon petroleum (or fossil fuels), energy consumption is typically measured in terms of tonnes (or barrels) of oil equivalent; the efficiency of a country's transport is then considered from this viewpoint. A variable of interest in order to measure the potential for a dramatic increase in energy consumption following economic growth is energy consumption relative to GDP, i.e. the ratio between energy consumption of transport and GDP at the year 2000 exchange rate (IEA 2010). 
We now address the issue of energy consumption in relation to transport mode: Figure 1 shows the association between energy consumption relative to GDP and train share in passenger land transport in Germany, for the years 1991-2007 (data available from EUROSTAT).

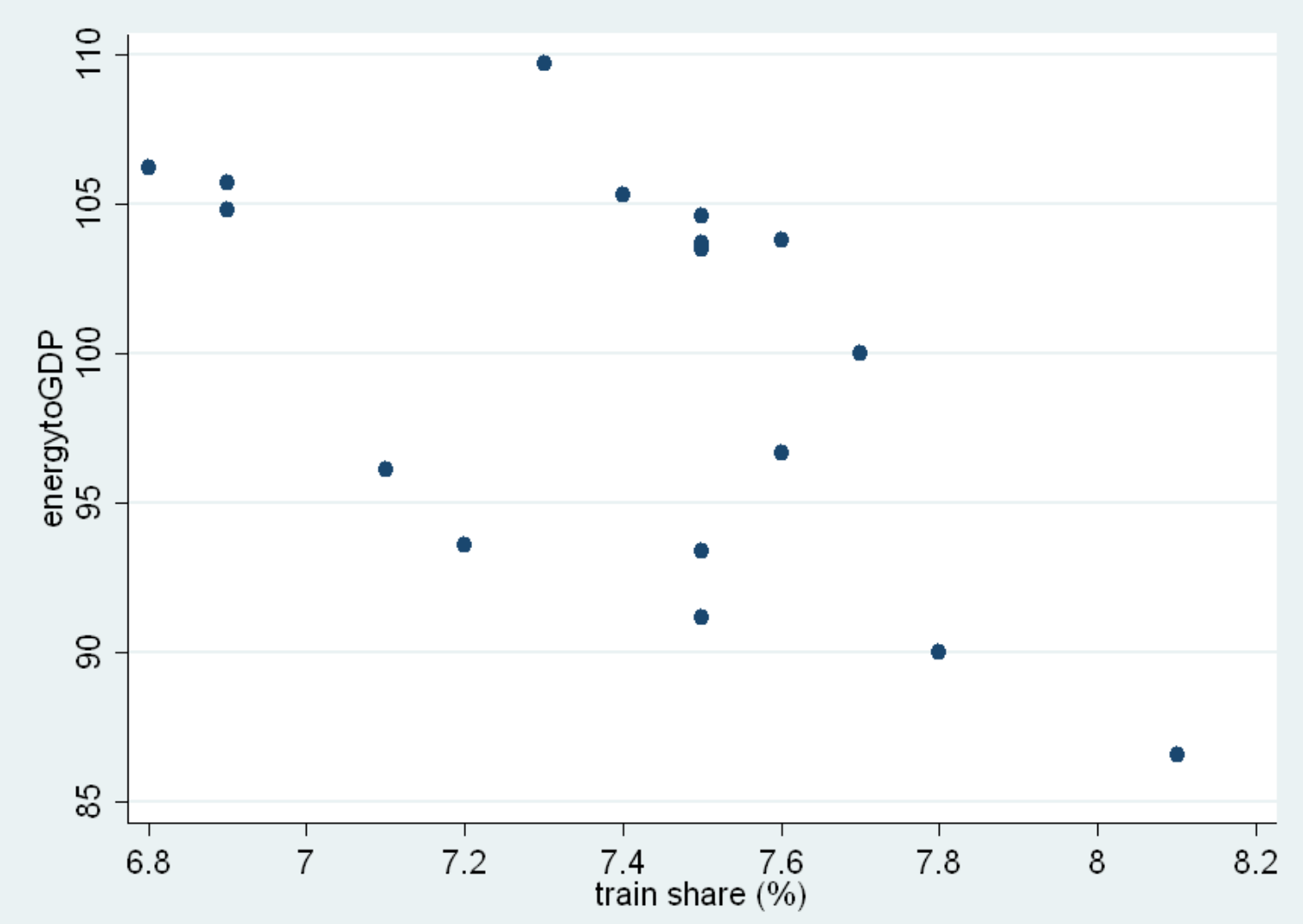

Figure 1: Association between energy relative to GDP and train share in land transport in Germany (1996-2004)

The correlation between these two quantities is strong and significant (-0.5659), suggesting that the use of trains as a mode of transport provides relevant outcomes in terms of car-use reduction. These results are supported by evidence at the EU level. By analysing the (former) EU-15 countries for the period 1990-2008, we find a significant relationship (even after controlling for country-specific stable characteristics) both between car share and greenhouse gases emissions, and between train share and energy consumption relative to GDP (as expected, positive in the former case, and negative in the latter), as shown in Appendix 1. 
However, from IAB data it appears that commuting by car in Germany has slightly increased in the period 1996-2004, while use of the public transport mode has been quite stable. If we look at the total amount of commuting, there was a rise in the first half of the same period, while, after 2001, flows appear rather stable. A possible explanation of the increase of the mode car as opposed to public transport might be that the new jobs are located in non-accessible locations by public transport, where car use becomes necessary for the commuter (see also Maat and Timmermans 2009).

To sum up, our results bring to light that, in Germany, commuting flows have a positive and robust effect on employment in the receiving labour market districts, and that the train (compared with the car) is an environmentally-benign mode of transport in reducing energy consumption, at least for the period considered. Thus, we may argue that, first, commuting which creates more flexibility (and hence efficiency) in local and regional labour markets should be encouraged. Secondly, an increase of commuters would make the transport mode chosen more crucial for sustainability, calling for an improvement of the public transport system (that may, in turn, increase commuting). Therefore, in this context, particular attention should be paid to the effect of city network structures on pollution emission from commuting (see, e.g., recent contributions by Glaeser and Kahn 2010). This issue is crucial, making it possible both to increase sustainability and to generate positive economic effects; in particular, providing more opportunities for commuting flows may lead to better employment perspectives for local and regional workers. Germany seems to have a tendency towards a polycentric commuting network (Reggiani et al. 2011), and may thus be oriented towards an increase of intra-urban commuting flows. Further development of typologies of economic network development is thus a sine qua non for the analysis of an ecologically and socioeconomically 'optimal' urban system.

\section{Conclusions}

We live in an urban century, in which spatial mobility and urbanization are important force fields. Commuting is on a rising edge, as it opens up new opportunities for many people. Cities are nodal hubs in a complex geographical network, and are hence able to attract many commuters, even from a long distance.

In this paper, with reference to the specific context of German regions, we have empirically shown that commuting may positively affect local labour market outcomes, and thus the economy as a whole. It was also found that the German economic activities are 
accompanied by negative environmental externalities, which are clearly associated with a specific transport mode, viz. the car. The sustainability issue appears, therefore, to be a common umbrella under which the relationship 'economy-transportation' - that is still a subject for debate and not easy to formally elaborate - certainly plays a joint role, since these two main variables (economy and transport) show similar negative environmental externalities. In this context, more theoretical work is needed in order to formulate and finalize the circular relationship 'economy-transport-environmental performance': for example, by means of an appropriate production functions approach and/or by non-linear dynamic simulation.

From the methodological viewpoint, the use of instrumental variables has shown the potential of this method to address the issue of the possible bias induced by the endogeneity of commuting inflows to employment outcomes. However, more appropriate data and further analysis are necessary in order to obtain accurate estimates of such effects, also with respect to informing policies related to commuting.

From a strategic viewpoint, the above-mentioned empirical results suggest that efficient public transport on a local/regional scale may play an important role in achieving sustainability, to be expanded in the future.

\section{Acknowledgements}

The authors wish to thank Anette Haas and Uwe Blien (IAB, Germany) for kindly providing the data set, and Giovanni Russo (at CEDEFOP: European Centre for the Development of Vocational Training) for his suggestions on the Instrumental Variables models. One anonymous referee is also acknowledged for valuable comments and suggestions.

\section{References}

Angrist, J., Krueger, A., Instrumental Variables and the Search for Identification: From Supply and Demand to Natural Experiments, Journal of Economic Perspectives, vol.15, no. 4, 2001, pp. 69-85

Bakker, P., Koopmans, C., Nijkamp, P., Appraisal of Integrated Transport Policies, Integrated Transport (M. Givoni and D. Banister, eds), Routledge, London, 2010, pp. 117-136

Banister, D., Stead, D., Steen, P., Åkerman, J., Dreborg, K., Nijkamp, P., Schleicher-Tappeser, R., European Transport Policy and Sustainable Mobility, Spon, London, 2000

Behrens, K., Mion, G., Murata, Y., Suedekum, J., Spatial Frictions. CEPR Discussion Paper No. DP8572. Available at SSRN: http://ssrn.com/abstract=1931081, 2011 
Berg, H., Burger, A., Thiele, K., Environmentally Harmful Subsidies in Germany, Federal Environment Agency, Dessau-Rosslau, Germany, 2010

Black, W.R., Nijkamp, P. (eds), Social Change and Sustainable Transport, Indiana University Press, Bloomington and Indianapolis, 2002

Brandt, T., Liberalisation and Privatisation in the German Electricity Sector, Pique Country Reports on Liberalisation and Privatisation Processes and Forms and Regulations, 2006

Brown, B., Modal Choice, Location Demand, and Income, Journal of Urban Economics, vol. 20, no.2, 1986, pp.128-139

Buehler, R., Promoting Public Transportation: A Comparison of Passengers and Policies in Germany and the U.S., Transportation Research Record: Journal of the Transportation Research Board, No. 2110, 2009, pp. 60-68

Burdett, K., Mortensen, D.T., Wage Differentials, Employer Size, and Unemployment, International Economic Review, vol. 39, no. 2, 1998, pp. 257-273

Card, D., DiNardo, J., Do Immigrant Inflows Lead to Native Outflows? American Economic Review, vol. 90, no. 2, 2000, pp.360-367

Cervero, R., Mixed Land-Uses and Commuting: Evidence from the American Housing Survey, Transportation Research A, vol. 30, no. 5, 1996, pp. 261-377

Chapman, L., Transport and Climate Change: a Review, Journal of Transport Geography, vol. 15, no. 5, 2007 , pp. 354-367

EPC WORKING PAPER N.16, 12 Prescriptions for a European Sustainable Mobility Policy, the EPC Task Force on Transport, 2005

EU, Guidelines - Developing and Implementing a Sustainable Urban Mobility Plan, 2011. Downloadable at: http://www.mobilityplans.eu/docs/SUMP_guidelines_web0.pdf

Gaignè, C., Riou, S., Thisse, J.-F, Are Compact Cities Environmentally Friendly?, CEPR Discussion Paper no. 8297, Paris, March 2011

Geurs, K.T., van Wee, B., Ex-post Evaluation of Thirty Years of Compact Urban Development in the Netherlands, Urban Studies, vol. 43, no. 1, 2006, pp. 139-160

Glaeser, E. L., Kahn, M. E., The Greenness of Cities: Carbon Dioxide Emissions and Urban Development, Journal of Urban Economics, vol. 67, 2010, pp. 404-418

Griliches, Z., Hausman, J., Errors in variables in panel data, Journal of Econometrics, Elsevier, vol. 31(1), 1986, pp. 93-118.

Gutiérrez-i-Puigarnau, E., van Ommeren, J. N., Labour Supply and Commuting, Journal of Urban Economics, vol. 68 , no.1, 2010, pp. 82-89

Hazans, M., Commuting in the Baltic States: Patterns, Determinants and Gains, Working paper B02-2003, ZEI (Center for Integration Studies, University of Bonn), 2003

Hazans, M., Does Commuting Reduce Wage Disparities?, Labor and Demography 0509012, EconWPA, 2005

Heckmann, J. J., Honoré, B. E., The Empirical Content of the Roy Model, Econometrica, vol. 58, no. 5, 1990, pp. 1121-1149

Hirte, G., Tscharaktschiew, S., Should Subsidies to Urban Passenger Transport be Increased? A Spatial CGE Analysis for a German Metropolitan Area, 2011. Available at SSRN: http://ssrn.com/abstract=1765302 or doi:10.2139/ssrn.1765302

IEA, International Energy Agency, $\mathrm{CO}_{2}$ Emissions from Fuel Combustion. Highlights, 2010 Edition. Available at: www.iea.org /co2highlights

Infante, D., Smirnova, J., Some Notes on Modelling the Relationship between the Environment and Institutional Context, Modern Economy, vol. 2, no. 1, 2011, pp. 18-24

Jolivet, G., Postel-Vinay, F., Robin, J.-M, The Empirical Content of the Job Search Model: Labor Mobility and Wage Dispersion in Europe and the U.S., European Economic Review, vol. 50, no. 4, 2006, pp. 877-907

Kenworthy, J., Murray-Leach, R., Townsend, C., Sustainable Cities - the Challenge of the 21st Century, The Natural Advantage of Nations (Vol. I): Business Opportunities, Innovation and Governance in the 21st Century, The Natural Edge Project, Earthscan, London, 2005

Kuznets, S., Economic Growth and Income inequality, American Economic Review, vol. 49, no. 1, 1955, pp. 128 
Li, X., Shao, C., Yang, L., Simultaneous Estimation of Residential, Workplace Location and Travel Mode Choice based on Nested Logit Model, Paper presented at the 7th International Conference on Fuzzy Systems and Knowledge Discovery, Yantai, Shandong, China, 10-12 August 2010. Available at: http://ieeexplore.ieee.org/xpl/mostRecentIssue.jsp?punumber=5562238

Maat, K., Timmermans, H.J.P., Influence of the Residential and Work Environment on Car Use in Dual-Earner Households, Transportation Research A, vol. 43, no. 7, 2009, pp. 654-664

McFadden, D., The Measurement of Urban Travel Demand, Journal of Public Economics, vol. 3, no. 4, 1974, pp. 303-328

Mincer, J., Schooling, Experience and Earnings, Columbia University Press, New York, 1974

Nijkamp, P., Reggiani, A., The Economics of Complex Systems, Springer-Verlag, Berlin, 1998

Nijkamp, P., Rienstra, S., Vleugel, J., Transportation Planning and the Future, John Wiley, Chichester/New York, 1998

Nijkamp, P., Rodenburg, C., Ubbels, B., van Veen-Groot, D., Driving Forces and Threats for Sustainable Transport, Built Environment, vol. 26, no. 3, 2001, pp. 236-257

Nijkamp, P., van Delft, H., van Veen-Groot, D., Sustainable Mobility and Globalisation: New Challenges for Policy Research, Economics of Globalisation (P. Gangopadhyay and M.Chatterji, eds), Ashgate, Aldershot, pp. 67-76, 2005

Nijkamp, P., Borzacchiello, M.T., Ciuffo, B., Torrieri, F., Sustainable Urban Land Use and Transportation Planning: A Cognitive Decision Support System for the Naples Metropolitan Area, International Journal of Sustainable Transportation, vol. 1, no. 2, 2007, pp. 91-114

Norwood, J., Casey, J., Workshop Agenda and Participants. Key Transportation Indicators: Summary of a Workshop. Washington, DC: The National Academies Press, 2002

Patuelli, R., Reggiani, A., Nijkamp, P., Schanne, N., Neural Networks for Regional Employment Forecasts, Journal of Geographical Systems, vol.13. no.1, 2011, pp. 67-85.

Pearl, J., Causality: Models, Reasoning, and Inference. Cambridge University Press, Cambridge (UK), 2000

Percoco, P., Reggiani, A., Environmental Awareness and Rail Passenger Transport in Europe, Rail Transport and the Environment (M. Ledbury, E. Schänzler and J. Ludewig, eds), CER, Bruxelles, 2008, pp.161-177

Pierrard, O., Commuters, Residents and Job Competition, Regional Science and Urban Economics, vol. 38, no.6, 2008, pp. 565-577

Postel-Vinay, F., Robin, J.M., Equilibrium Wage Dispersion with Worker and Employer Heterogeneity, Econometrica, vol. 70, No. 6, 2002, pp. 2295-2350

Postel-Vinay, F., Turon, H., On-the-job Search, Productivity Shocks, and the Individual Earnings Process, CEPR Discussion Paper no. 5593, 2005

Reggiani, A., Nijkamp, P. (eds), Complexity and Spatial Networks, Springer-Verlag, Berlin, 2009

Reggiani, A., Bucci, P., Russo, G., Haas, A., Nijkamp, P., Regional Labour Markets and Job Accessibility in City Network Systems in Germany, Journal of Transport Geography, vol. 19, n. 4, 2011, pp. 528-536

Rouwendal, J., Nijkamp, P., Homeownership and Labour-market Behaviour: Interpreting the Evidence, Environment \& Planning A, vol. 42, no. 2, 2010, pp. 419-433

Russo, G., Tedeschi, F., Reggiani, A., Nijkamp, P., Commuter Effects on Local Labour Markets: A German Modelling Study, Paper presented at the ERSA Conference in Jonkoping, Sweden, 19-23 August 2010

Shields, M., Shideler, D., Do Commuters Free-Ride? Estimating the Impacts of Interjurisdictional Commuting on Local Public Goods Expenditures, Journal of Regional Analysis and Policy, 33 (1), 27-42, 2003

Shields, M., Swenson, D., An Industry-level Analysis of Commuting Response to Employment Growth, Journal of Regional Analysis and Policy, vol. 30, no. 2, 2000, pp. 81-94

Simpson, W., Urban Structure and the Labour Market: Worker Mobility, Commuting and Underemployment in Cities, Clarendon Press, Oxford, 1992

Sorek, G., Migration Costs, Commuting Costs and Intercity Population Sorting, Regional Science and Urban Economics, vol. 39, no. 4, 2009, pp. 377-385

Stathopoulos, A., Valeri, E., Marcucci, E., Gatta, V., Nuzzolo, A., Comi, A., Urban Freight Policy Innovation for Rome's LTZ: A Stakeholder Perspective, in Macharis,C., and Melo, S. (Eds.), Multiple Views on City Distribution: a State of the Art, Edward Elgar Publishing, London, UK, 2011

Stutzer, A., Frey, B.S, Stress That Doesn't Pay: The Commuting Paradox,. Scandinavian Journal of Economics, $100(2), 2008,339-366$ 
Travisi, C., Camagni, R., Nijkamp, P., Impacts of Urban Sprawl and Commuting: A Modelling Study for Italy, Journal of Transport Geography, vol. 18, no.3, 2010, pp. 382-392

Van Geenhuizen, M., Black, W.R., Nijkamp, P., Social Change and Sustainable Transport: A Manifesto on Transatlantic Research Opportunities, Social Change and Sustainable Transport (W.R. Black and P. Nijkamp, eds), 2002, Indiana University Press, Bloomington and Indianapolis, pp. 3-16

WBCSD, World Business Council for Sustainable Development, Mobility 2001: World Mobility at the End of the Twentieth Century and Its Sustainability, 2001. Available at: www.wbcsdmotability.org

Woodcock, J., Banister, D., Edwards, P., Prentice, A.M., Roberts, I., Energy and Transport, The Lancet, vol. 370, 2007, pp. 1078-1088. Available at: $\underline{w w}$. thelancet.com 


\section{Appendix 1}

In this Appendix, correlation coefficients between three environmental variables ((a) energy consumption in tonnes of oil equivalent, in absolute values; (b) energy consumption in tonnes of oil equivalent, relative to $G D P$, and (c) emissions of greenhouse gases in thousands of tonnes of $\mathrm{CO}_{2}$ equivalent) and the share of car and train passengers in total inland transport are presented, together with the associated $p$-values (countries: former EU-15; years: 1990-2008).

Table 1A: Correlations (and associated p-values of the simple regressions) between mode of transport and environmental variables (countries: former EU-15; years: 1990-2008).

\begin{tabular}{llccc} 
VARIABLES & Energy & Energy to GDP & $\begin{array}{c}\text { Greenhouse } \\
\text { Gases }\end{array}$ & $\begin{array}{c}\text { Carbon dioxide } \\
\text { emissions }\end{array}$ \\
\hline CAR & 0.39 & 0.20 & 0.51 & 0.37 \\
p-value & 0.112 & 0.517 & $0.030^{* *}$ & 0.194 \\
TRAIN & 0.30 & -0.80 & 0.15 & -0.76 \\
p-value & 0.225 & $0.001^{* * *}$ & 0.545 & $0.002^{* * *}$
\end{tabular}

Notes: *** significant at the $1 \%$ level, $* *$ significant at the $5 \%$ level, *significant at the $10 \%$ level. 


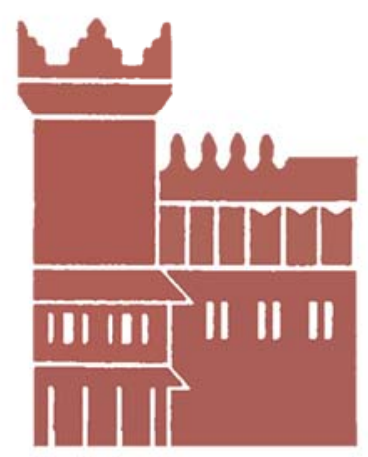

Alma Mater Studiorum - Università di Bologna DEPARTMENT OF ECONOMICS

Strada Maggiore 45

40125 Bologna - Italy

Tel. +39051 2092604

Fax +390512092664

http://www.dse.unibo.it 